\title{
Multi-level decomposition of ASEAN urbanization effects on energy
}

\author{
Khuong, Phuong Minh; McKenna, Russell; Fichtner, Wolf
}

Published in:

International Journal of Energy Sector Management

Link to article, DOI:

10.1108/IJESM-12-2018-0002

Publication date:

2019

Document Version

Peer reviewed version

Link back to DTU Orbit

Citation (APA):

Khuong, P. M., McKenna, R., \& Fichtner, W. (2019). Multi-level decomposition of ASEAN urbanization effects on energy. International Journal of Energy Sector Management, 13(4), 1107-1132. https://doi.org/10.1108/IJESM12-2018-0002

\section{General rights}

Copyright and moral rights for the publications made accessible in the public portal are retained by the authors and/or other copyright owners and it is a condition of accessing publications that users recognise and abide by the legal requirements associated with these rights.

- Users may download and print one copy of any publication from the public portal for the purpose of private study or research.

- You may not further distribute the material or use it for any profit-making activity or commercial gain

- You may freely distribute the URL identifying the publication in the public portal 
See discussions, stats, and author profiles for this publication at: https://www.researchgate.net/publication/335218201

\section{Multi-level decomposition of ASEAN urbanization effects on energy}

Article in International Journal of Energy Sector Management · August 2019

DOI: 10.1108/IJESM-12-2018-0002

\section{CITATION}

1

3 authors:

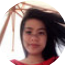

Phuong Khuong

Electric Power University

4 PUBLICATIONS 17 CITATIONS

SEE PROFILE

(9)

Wolf Fichtner

Karlsruhe Institute of Technology

330 PUBLICATIONS 3,768 CITATIONS

SEE PROFILE
110 PUBlications 1,370 CITATIONS

SEE PROFILE

Some of the authors of this publication are also working on these related projects:

ESA2 - Energy System Analysis Associates View project

Combining local preferences with multi-criteria decision analysis and linear optimisation to develop feasible energy concepts in small communities View project 


\title{
Multi-level decomposition of ASEAN urbanization effects on energy
}

\section{Phuong Minh Khuong}

Chair of Energy Economics, Karlsruhe Institute of Technology, Karlsruhe, Germany

Russell McKenna

Department of Technology, Management and Economics, Technical University of Denmark, Kongens Lyngby, Denmark, and

\author{
Wolf Fichtner \\ Chair of Energy Economics, Karlsruhe Institute of Technology, \\ Karlsruhe, Germany
}

\begin{abstract}
Purpose - The connection between urbanization and energy consumption in the context of cross-country and cross-sector analyses is poorly understood, especially in the Association of South East Asian (ASEAN). This paper aims to present the first extensive multi-level analysis of the relationship between urbanization and energy consumption in ASEAN countries from 1995 to 2013.

Design/methodology/approach - The multi-level (across country and sector) index decomposition method is used to analyze urbanization, energy mix, energy intensity and activity effects on energy demand. Urbanization is measured by two representative factors, name the urban population and the number of nonagriculture workers.

Findings - Despite the decreasing rate of urbanization, its effect on energy consumption has played the most important role since 2000. Since then, the effect has continued to increase at the national and sectoral levels across the whole region. The strongest urbanization impacts are encountered in the residential sector, followed by transportation and industrial sectors with much weaker effects in the commercial sector. The way in which urbanization impacts energy consumption depends strongly on the income level of the country studied.

Practical implications - The results provide quantitative relationships between urbanization and energy demand. For example, if the urban population and the non-agriculture workers decreased by 0.1 per cent per year, this would reduce energy demand by 1.4 per cent and 2.6 per cent per year respectively.

Originality/value - This contribution provides detailed quantitative insights into the relationships between urbanization and energy demand at sectoral, national and international levels, which are invaluable for policymakers in the region.
\end{abstract}

Keywords Decision-making, Energy sector, ASEAN, Urbanization, End-use models, Decomposition, Energy conversion, Energy balance

Paper type Research paper

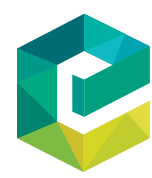

Received 17 December 2018

Revised 20 February 2019

3 May 2019

Accepted 5 May 2019

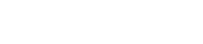




\section{IJESM}

Figure 1.

Average annual GDP growth rate over the World and ASEAN from 1995-2017

\section{Introduction}

The relationship between energy consumption, economic and demographic changes has been intensively researched, especially for emerging economies such as India and China. Much of this research addresses the challenge of ensuring sustainable development, in the context of resource shortages and reduced environmental quality, while maintaining economic growth (Wang et al., 2013, Wang, 2014, Pachauri and Jiang, 2008, etc.).

These issues also burden many other developing countries such as ASEAN (the Association of South East Asian Nations), whose economy has been growing rapidly since the mid-1980s and has become a growth engine of the global economy[1] (see Figure 1). ASEANs' GDP growth rate is projected to continue to increase at on average 5.2 per cent over the period 2019-2023 (Economic Outlook, 2019). In its 5th State of the Environment Report (SOER 5th, 2017) ASEAN identified the urgent situation of air and solid polution in the region as a result of uncontrolled rapid development. As member countries pursue their economic goals, ASEANs' energy demand is projected to more than double and $\mathrm{CO}_{2}$ emissions to triple by 2040 (ASEAN Energy Outlook, 2017), which would worsen the alarming level of pollution in most of the ASEAN countries due to increasing fossil fuel consumption (Global megatrends, AIMD, 2017).

While ASEAN countries have attempted to lessen these problems, a new challenge may be arising in the form of naturally rapid urbanization. Recently, urbanization (refer to section 2 for a detailed definition) in ASEAN has been considerably increasing by 3 per cent per year during the period 1995-2014, higher than the average global rate of 2 per cent per year. Futher urban growth is expected in ASEAN, with the projected percentage of urbanites increasing from today's 47 per cent to 56 per cent in 2030 and 67 per cent in 2050 respectively (UN, 2014). ASEAN governments are finding it difficult to cope with the rapid increases in the urban population, resulting in serious energy-related environmental problems, especially in the pressure of growing demands for constructing basic infrastructure (SOER 5th, 2017).

However, a superficial look shows that energy consumption seems to increase faster in the country with the lower annual urban growth rate in ASEAN, except for the Philippines (see Figure 2). It could mean urbanization reduces energy consumption, and therefore reduces its effects on the environment. Moreover, as urbanization is the main

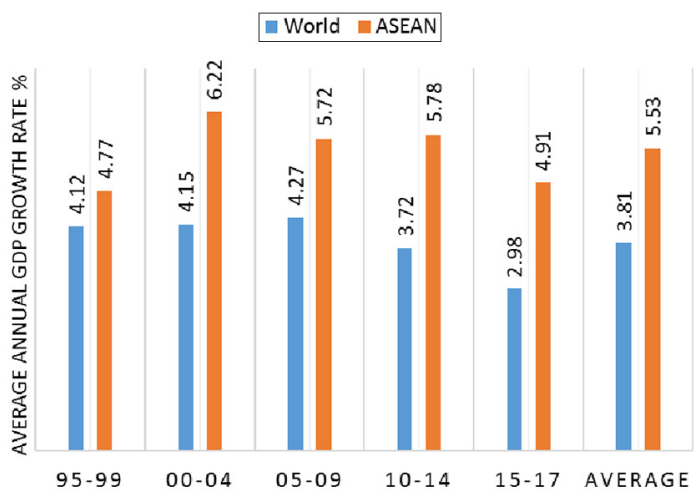

Source: Own calculation based on the database of World Bank, last accessed (3 December 2018) 


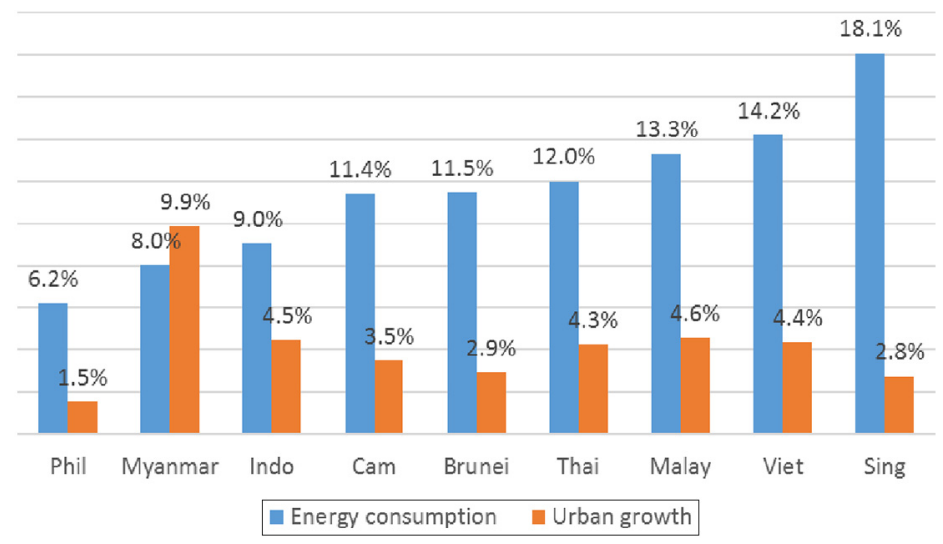

Source: Own calculation based on database of World Bank (2018) and IEA (2018) last accessed (1 December 2018)

\section{ASEAN urbanization effects on energy}

Figure 2.

Average annual energy consumption and urbanization growths in ASEAN between 1995 and

2014

factor driving renewable energy development in the region (Khuong et al., 2019), it may speed up the energy transition process towards higher shares of renewables in the total energy mix, and therefore help to reduce the effect of increasing energy consumption on the environment.

The two possible and contradictory effects of urbanization on energy consumption reveal a problem of lacking or incomplete knowledge on this issue that could impede ASEANs progress towards achieving their sustainable development goals (Global megatrends, AIMD, 2017). Moreover, as ASEAN has deepened cooperation in sustainable development (ASEAN Community Vision 2025), it is necessary to extend the investigation of the effects on energy consumption not only in national sectoral interactions but also international interactions. The literature review in Section 2 illustrates the research gap in comparing the differential impact of urbanization on energy consumption across countries and sectors, as well as discussing the decomposition method over the regression method for investigating the problem. Answering this and related questions is of primary importance for academics and ASEAN policy makers to make a horizontal and vertical scan of the effect on international-national-sectoral scales.

With this purpose, this paper proposes the multi-level Index Decomposition Analysis (IDA) capable of cross-country-sector comparison to investigate the issues related to the relationship between energy consumption, economic growth and urbanization. The paper aims to:

- estimate the urbanization effect and the other contributing effects (population, economic development etc.) on energy consumption changes;

- compare the effects at multi-levels between ASEAN countries; and

- propose some suggestions for policy makers in the context of economic development and urbanization.

The remainder of the paper is structured as follows. Section 2 presents a literature review and thus demonstrates the gaps filled by this study. Section 3 introduces components of the dataset and explains the methodology for assessing the urbanization 
effect. Section 4 provides the results from multi-level analyses. Section 5 discusses the effects of demographic factors on energy consumption and critically reflects on the methodology used in this paper. Finally, section 6 gives a conclusion and outlook, including some suggestions for policymakers about urbanization-energy issues and further research requirements.

\section{Literature review}

This section aims to review, summarize, and synthesize the arguments and ideas of previous research that focused on analyzing the relationship between urbanization and energy consumption (see Figure 3). After scrutinizing these studies, we identified certain research areas that have been given little attention in this area. These areas are highlighted in blue in Figure 3 to demonstrate this paper's novelties, and a detailed explanation is given in the following sections.

\subsection{Issue 1 - lacking multi-level comparisons in research scope}

As shown in the first column of Figure 3, previous research mostly focused on proving and comparing the effects of urbanization on energy consumption between countries with similar economic conditions, such as in developed countries (Parikh and Shukla, 1995; Liddle and Lung, 2014; York, 2007), and developing countries (Jones, 1989, 1991; Madlener and Sunak, 2011; Mishra et al., 2009; LENZEN et al., 2006). Or they investigated the relationship in one country within different energy consuming sectors such as Lariviere and Lafrance (1999) in Canada, Wang et al. (2013) in China, Halicioglu (2007) in Turkey, Ewing and Rong (2008) in the USA.

Some researchers investigated the effect between different countries for one sector such as transportation, agriculture (Jones, 1991; Liddle and Lung, 2014; Poumanyvong and Kaneko, 2010), building energy consumption (Li and Yao, 2009) and national residential energy use (Holtedahl and Joutz, 2004; Poumanyvong et al., 2012b).

However the comparison of relative impacts of urbanization between sector-sector and sector-country has not been carried out in general, as well as specifically for ASEAN.

\subsection{Issue 2 - limited results due to the method}

2.2.1 Revealing general relationships but not individual factor contributions. The regression analysis with dynamic and statistical models was used in most studies in this field, accounting for 34/45 studies. However, this method can reveal general relationships but not individual factor contributions (Liu, 2009). Liu (2009) concluded that using regression showed only unidirectional Granger causality between China's urbanization and its total energy consumption, but to find out the contribution share of urbanization on energy consumption required a decomposition analysis.

2.2.2 Obstacles in data processing and analysis. Regression requires large data sets, which are quite challenging to obtain for developing countries (Zeng et al., 2017), such as ASEAN, where the database has only been developed over the past 15 years or so. Moreover, regression models using cross-sectional data (Jones, 1991; York, 2007; York et al., 2003) as well as timeseries data (Liu, 2009; Holtedahl and Joutz, 2004), and even panel data (Poumanyvong et al., $2012 \mathrm{~b})$ typically overlook the comparison with the base year, i.e. using data with current currency instead of constant currency [purchasing power parity (PPP)]. Liu (2009), York (2007) and Zeng et al. (2017) claimed the method runs into difficulties when dealing with unbalanced data (i.e. a panel that has some missing data for at least one year or one period, or for at least one entity), and nonlinear data in explaining the relationship and the changes. 


\begin{tabular}{|c|c|c|c|c|c|c|c|c|c|c|c|c|c|c|c|c|c|}
\hline \multirow[b]{2}{*}{ Author, year } & \multicolumn{5}{|c|}{ Research scope } & \multicolumn{3}{|c|}{ Method } & \multicolumn{6}{|c|}{ Considered relationships } & \multicolumn{2}{|c|}{ Results } & \multirow[t]{2}{*}{ Purpose } \\
\hline & M & $\mathbf{C}$ & $\mathbf{P}$ & $\mathbf{S}$ & $\mathrm{L}$ & $\mathbf{R}$ & $\mathbf{O}$ & $\mathrm{D}$ & GDP & EC & $\mathbf{E m}$ & In & EI & Others & $\mathbf{S}$ & $\mathbf{L}$ & \\
\hline Parikh, Shukla 1995 & $\mathrm{X}$ & & & & & $\mathrm{X}$ & & & $\mathrm{X}$ & $\mathrm{X}$ & & & & & + & & Sus \\
\hline Imai 1997 & $\mathrm{X}$ & & & & & $\mathrm{X}$ & & & $\mathrm{X}$ & $\mathrm{X}$ & & & & & + & & \\
\hline York 2007 & $\mathrm{X}$ & & & & & $\mathrm{X}$ & & & $\mathrm{X}$ & $\mathrm{X}$ & & & & & + & + & ED \\
\hline Lenzen et al. 2006 & $\mathrm{X}$ & & & & & $\mathrm{X}$ & & & $\mathrm{X}$ & $\mathrm{X}$ & & & & & $-/+$ & & Sus \\
\hline Fang et al. 2012 & $\mathrm{X}$ & & & & & $\mathrm{X}$ & & & $\mathrm{X}$ & $\mathrm{X}$ & & & & & - & & $\mathrm{CC}$ \\
\hline Liddle, Lung 2014 & $\mathrm{X}$ & & & & & $\mathrm{X}$ & & & $\mathrm{X}$ & $\mathrm{X}$ & & & & & - & & Sus \\
\hline Jones 1989 & $\mathrm{X}$ & & & & & $\mathrm{X}$ & & & $\mathrm{X}$ & $\mathrm{X}$ & $\mathrm{X}$ & & & & + & & Eco \\
\hline Poumanyvong, Kaneko 2010 & $\mathrm{X}$ & & & & & $\mathrm{X}$ & & & $\mathrm{X}$ & $\mathrm{X}$ & $\mathrm{X}$ & & & & & + & Sus \\
\hline Sharif Hossain 2011 & $\mathrm{X}$ & & & & & $\mathrm{X}$ & & & $\mathrm{X}$ & $\mathrm{X}$ & $\mathrm{X}$ & & & & & + & Eco \\
\hline Poumanyvong et al. 2012 & $\mathrm{X}$ & & & & & $\mathrm{X}$ & & & $\mathrm{X}$ & $\mathrm{X}$ & $\mathrm{X}$ & & & & & + & Eco \\
\hline Al-mulali et al. 2013 & $\mathrm{X}$ & & & & & $\mathrm{X}$ & & & & $\mathrm{X}$ & $\mathrm{X}$ & & & & + & & Sus \\
\hline Sadorsky 2013 & $\mathrm{X}$ & & & & & $\mathrm{X}$ & & & $\mathrm{X}$ & & & $\mathrm{X}$ & $\mathrm{X}$ & & & $\overline{1+}$ & $\mathrm{CC}$ \\
\hline Li, Lin 2015 & $\mathrm{X}$ & & & & & $\mathrm{X}$ & & & $\mathrm{X}$ & $\mathrm{X}$ & $\mathrm{X}$ & $\mathrm{X}$ & & $\mathrm{X}$ & $-/+$ & & Eco \\
\hline Asif et al. 2015 & $\mathrm{X}$ & & & & & $\mathrm{X}$ & $\mathrm{X}$ & & $\mathrm{X}$ & $\mathrm{X}$ & & $\mathrm{X}$ & & & & + & Eco \\
\hline Burney 1995 & $\mathrm{X}$ & & & & & & $\mathrm{X}$ & & $\mathrm{X}$ & $\mathrm{X}$ & & & & & + & & Eco \\
\hline Mishra et al. 2009 & $\mathrm{X}$ & & & & & & $\mathrm{X}$ & & $\mathrm{X}$ & $\mathrm{X}$ & & & & & - & + & Eco \\
\hline Wang 2015 & $\mathrm{X}$ & & & & & $\mathrm{X}$ & & & & $\mathrm{X}$ & $\mathrm{X}$ & & & & & + & Sus \\
\hline Zhang et al. 2017 & $\mathrm{X}$ & & & & & $\mathrm{X}$ & & & $\mathrm{X}$ & $\mathrm{X}$ & $\mathrm{X}$ & & & $\mathrm{X}$ & & & $\mathrm{RE}$ \\
\hline Jones 1991 & & $\mathrm{X}$ & & & & $\mathrm{X}$ & & & $\mathrm{X}$ & & & $\mathrm{X}$ & $\mathrm{X}$ & & + & & ED \\
\hline Lin et al. 2008 & & $\mathrm{X}$ & & & & $\mathrm{X}$ & & & $\mathrm{X}$ & & & & & $\mathrm{x}$ & & + & $\mathrm{CC}$ \\
\hline Liu 2009 & & $\mathrm{X}$ & & & & $\mathrm{X}$ & & $\mathrm{X}$ & $\mathrm{X}$ & $\mathrm{X}$ & & & & $\mathrm{X}$ & + & $\sim$ & ED \\
\hline Ghosh, Kanjilal 2014 & & $\mathrm{X}$ & & & & $\mathrm{X}$ & & & $\mathrm{X}$ & $\mathrm{X}$ & & & & & & $\sim$ & Sus \\
\hline Belloumi, Alshehry 2016 & & $\mathrm{X}$ & & & & $\mathrm{X}$ & $\mathrm{X}$ & & $\mathrm{X}$ & & & $\mathrm{X}$ & $\mathrm{X}$ & & + & + & ED \\
\hline Wei et al 2003 & & $\mathrm{X}$ & & & & & $\mathrm{X}$ & & $\mathrm{X}$ & $\mathrm{X}$ & & & & $\mathrm{X}$ & $-/+$ & & Eco \\
\hline Li et al. 2011 & & $\mathrm{X}$ & & & & & $\mathrm{X}$ & & $\mathrm{X}$ & $\mathrm{X}$ & & & & $\mathrm{X}$ & $-/+$ & & ED \\
\hline$O^{\prime}$ Neill et al. 2012 & & $\mathrm{X}$ & & & & & $\mathrm{X}$ & & $\mathrm{X}$ & $\mathrm{X}$ & $\mathrm{X}$ & & & & & $\sim$ & ED \\
\hline Yang et al. 2015 & & $\mathrm{X}$ & & & & & & $\mathrm{X}$ & $\mathrm{X}$ & $\mathrm{X}$ & & & & $\mathrm{X}$ & & $\overline{1+}$ & $\mathrm{RE}$ \\
\hline Franco 2017 & & $\mathrm{X}$ & & & & $\mathrm{X}$ & & & & $\mathrm{X}$ & $\mathrm{X}$ & & $\mathrm{X}$ & & & + & Sus \\
\hline Newman, Kenworthy 1998 & & & $\mathrm{X}$ & & & $\mathrm{X}$ & & & $\mathrm{X}$ & $\mathrm{X}$ & & & & & - & & Sus \\
\hline Wang 2014 & & & $\mathrm{X}$ & & & & & $\mathrm{X}$ & $\mathrm{X}$ & $\mathrm{X}$ & & & & $\mathrm{X}$ & & $\overline{1+}$ & $\mathrm{ED}$ \\
\hline Kenworthy, Laube 1996 & & & & $\mathrm{X}$ & & $\mathrm{X}$ & & & $\mathrm{X}$ & $\mathrm{X}$ & & & & & - & & Sus \\
\hline Isabelle Larivi ere 1999 & & & & $\mathrm{X}$ & & $\mathrm{X}$ & & & $\mathrm{X}$ & $\mathrm{X}$ & & & & & - & & ED \\
\hline Jiang, O'Neill 2007 & & & & $\mathrm{X}$ & & $\mathrm{X}$ & & & $\mathrm{X}$ & $\mathrm{X}$ & & & & & & & ED \\
\hline Ewing, Rong 2008 & & & & $\mathrm{X}$ & & $\mathrm{X}$ & & & $\mathrm{X}$ & $\mathrm{X}$ & & & & & - & & ED \\
\hline Adom et al. 2012 & & & & $\mathrm{X}$ & & $\mathrm{X}$ & & & $\mathrm{X}$ & $\mathrm{X}$ & & & & & + & & ED \\
\hline Li, Yao 2009 & & & & $\mathrm{X}$ & & $\mathrm{X}$ & & & & $\mathrm{X}$ & & & & $\mathrm{X}$ & & & ED \\
\hline Sun et al. 2014 & & & & $\mathrm{X}$ & & $\mathrm{X}$ & & & & $\mathrm{X}$ & & & & $\mathrm{x}$ & & + & ED \\
\hline Holtedahl, Joutz 2004 & & & & $\mathrm{X}$ & & $\mathrm{X}$ & $\mathrm{X}$ & & $\mathrm{X}$ & $\mathrm{X}$ & & & & & + & + & ED \\
\hline Halicioglu 2007 & & & & $\mathrm{X}$ & & $\mathrm{X}$ & $\mathrm{X}$ & & $\mathrm{X}$ & $\mathrm{X}$ & & & & $\mathrm{X}$ & & + & $\mathrm{ED}$ \\
\hline Shahbaz, Lean 2012 & & & & $\mathrm{X}$ & & $\mathrm{X}$ & $\mathrm{X}$ & & $\mathrm{X}$ & $\mathrm{X}$ & & $\mathrm{X}$ & & $\mathrm{X}$ & & + & ED \\
\hline Shen et al. 2005 & & & & $\mathrm{X}$ & & & $\mathrm{X}$ & & & $\mathrm{X}$ & & & & & + & & Eco \\
\hline Jiang, Lin 2012 & & & & $\mathrm{X}$ & & & $\mathrm{X}$ & & & $\mathrm{X}$ & & $\mathrm{X}$ & & & & + & Eco \\
\hline Fan et al. 2017 & & & & $\mathrm{X}$ & & & & $\mathrm{X}$ & $\mathrm{X}$ & $\mathrm{X}$ & & & $\mathrm{X}$ & & & + & ED \\
\hline Liu et al. 2018 & & & & $\mathrm{X}$ & & & & $\mathrm{X}$ & $\mathrm{X}$ & $\mathrm{X}$ & & & & & & + & ED \\
\hline
\end{tabular}

\section{ASEAN urbanization effects on energy}

Notes: Acronyms - Scope: M: Multi-country, C: Country, P: Province, S: Sector, L: Linking between multi-country and country and sector levels. Method: R: Regression, O: Other methods, D: Decomposition. Considered relationship: GDP: gross domestic product, EC: energy consumption, Em: emission, In: industrialization, EI: energy intensity. Results: S: short term, L: long term, +: Positive effect, -: negative effect Purpose: ED: energy demand, Eco: Economic development, Sus: sustainable development, CC: climate change. Blue column: covered by this research

Figure 3. Summary of relevant literature on the relationship between urbanization and energy consumption 
Furthermore, when analyzing individual sectors or whole countries, many approaches overlook the volatility and interactions among types of energy users. The combined resource requirements of energy input in manufacturing and transportation activities, for example, may increase energy consumption end-used but reduce energy utilization in residential areas. This offsetting impact could eliminate energy consumption fluctuations, i.e. it could erroneously imply unchanged or only slightly changed total energy consumption. If only the total energy consumption is considered, the regression typically overlooks the hidden effect from this phenomenon such as inefficient energy use, and issues relating to energy system structure and economic structure.

\subsection{Issue 3 - partly conflicting results}

When considering multi-countries, the results often present contradictory effects (see Figure 3). Two-thirds of the reviewed studies revealed a positive correlation between urbanization and energy consumption in multi-country approaches as well as in sectorallevel research. For example, with the "fixed effect[2] "Jones (1989, 1991), Parikh and Shukla (1995), York (2007), Shahbaz and Lean (2012) and Elliott et al. (2014) determined an urbanization elasticity of around 0.29-0.66 for energy consumption. On the other hand, some studies identified a negative link between urbanization and energy consumption at country level such as Lariviere and Lafrance (1999) conducted for 45 cities in Canada, and Mishra et al. (2009) analyzed panel data for Pacific Islands from 1980-2005.

At the sector level, while some authors mention that urbanization causes several important reductions in residential energy use e.g. Ewing and Rong (2008) researching in the USA and Wang (2014) studying China, others (such as Holtedahl and Joutz, 2004) conclude that urbanization is responsible for energy use increasing in this sector. The same contradictory findings were obtained for the transportation sector between Liddle and Lung (2014), who showed a negative effect in 23 OECD countries and Poumanyvong et al. (2012a), who found a positive influence of urbanization in 92 countries.

The controversy in earlier literature can be at least partly ascribed to differences in methodologies, data and economical and/or regional characteristics. Therefore, it is necessary to investigate further the relationship between urbanization, energy use and other factors (such as GDP, industrialization, emissions) by placing it within a region-countrysector context.

\subsection{Issue 4 - the urbanization definition}

One of the common issues encountered in the research is the definition of "urbanization". Most of the previous studies (Jones, 1991, 1989, 2004; Parikh and Shukla, 1995) considered the variable "urbanization" as the number of people living in urban areas. The term "urbanization growth rate" is used to refer to the growth rate of urban population in each considered period. Urban areas are categorized by urban morphology such as cities, towns, conurbations or suburbs.

Other authors (Ewing and Rong, 2008) used several forms of urbanization when investigating urban effects on energy use, including the percentage of the population living in urban areas, the population density in urban areas, and the average apartment size, which more accurately reflects the specific energy consumption in the residential and commercial sectors (Liddle and Lung, 2014; Liu and Xie, 2013). In researching the residential sector, Pachauri and Jiang (2008) compared India and China and used the number of households as an urbanization indicator.

The influence of urbanization on energy consumption changes based on the urbanization form considered. Therefore, this paper uses the most common urban indicators in the 
research field, namely urban population, symbolized as Urban 1, and non-agriculture employee, symbolized as Urban 2, to conduct the investigation.

\subsection{The potential of decomposition analysis}

The decomposition analysis has frequently been used in energy-related studies from the late 1970s until the present to analyze the impact of changes in product mix on energy consumption (Ang and Zhang, 2000; Hoekstra and van den Bergh, 2003). It was introduced with two techniques for decomposing indicator changes, structural decomposition analysis (SDA), which analyzes the input-output effect, and the index decomposition approach (IDA), which compares different effect factors. In assessing the influence of urbanization on energy consumption, Liu (2009) suggested the decomposition method as a new approach.

Wang (2014) and Liu et al. (2018) applied SDA to investigate the effects of China's urbanization on residential energy consumption. Wang (2014) conducted independent research on household usage and product usage by dividing total energy consumption into residential energy consumption (REC) and production energy consumption (PEC). Liu et al. (2018) analyzed the changes in indirect (IEC) and direct (DEC) energy consumption in household. However, both studies suggested urbanization has a positive effect on household energy consumption.

Secondly, Yang et al. (2016) and Fan et al. (2017) used IDA to assess the impact of urbanization on renewable energy consumption growth and on residential energy consumption in China respectively. Yang et al. (2016) focused on the macro analysis and concluded that the urbanization effect is insignificant for renewable energy use, while Fan et al. (2017) concluded that urbanization contributes 15.4 per cent of the residential energy consumption increase.

This paper therefore uses decomposition analysis to investigate the contribution of urbanization to energy consumption growth with a multi-perspective analysis including national and sectorial comparison, order to explore the diverging influences from nations to sectors.

\section{Methodology}

\subsection{Method}

IDA is used in this study to implement index approach and to conduct time-series analysis and cross-country comparisons. An the advantage of IDA over SDA is a lower data requirement, and the ability to assess the effect of a shift in the economic shares and energy mix. Moreover, IDA is based on the specification of the decomposition, whereas SDA has focused attention on distinguishing a large number of input-output effects. IDA is suitable for a top-down approach, whereas SDA is suitable for a bottom-up approach (Hoekstra and van den Bergh, 2003; Wang et al., 2017).

As a result, with limited available data, this paper uses the IDA method with a top-down approach to break down energy consumption data to gain insight into its compositional subsystems such as sectorial energy demand (commercial, transportation, industrial, residential) in a reverse-engineering technique. The energy consumption characteristics are analyzed in detail until they are reduced to their base elements in terms of the effect of each factor on each sector. This paper separates five factors including activity change (activity effect), modification of activity composition (structure effect), changes in sectorial energy intensity (intensity effect), adjustment in used energy types (energy mix effect) and especially urbanization changes (urban effect).

This paper suggests two approaches to assess the urban effect. The first one examines the energy consumers and estimates all effects mentioned above, except for the structure 
effect. The second approach analyzes the structure effect by separating the activity effect into the two effects including structure and production effects, to provide more details of economic growth and economic structure change than the first case.

For the first approach, assume that $\mathrm{E}$ is an aggregate composed of $n$ factors $\left(x_{1}, \ldots, x_{\mathrm{n}}\right)$ and from period 0 to $T$ the aggregate changes from $E_{0}$ to $E_{t}$. The objective is to derive the contribution of the $n$ factors to the change in the aggregate, which can be expressed as given in equation (1):

$$
\Delta E_{t o t}=E_{t}-E_{0}=\Delta E_{x 1}+\ldots+\Delta E_{x n}+\Delta E_{r s d}
$$

Implementing the concept to analyze the effect of urbanization on energy consumption for each sector is given in equation (2):

$$
E_{j}=\sum_{i} \frac{E_{i j}}{E_{j}} \times \frac{E_{j}}{V A_{j}} \times \frac{V A_{j}}{D} \times D
$$

whereby:

$E_{i}$ : Energy consumption of energy type i (including fuel, electricity and renewables) in sector j;

$E_{j}$ : Total energy consumption in sector $\mathrm{j}$ (including commercial, industrial, residential, and transportation);

$V A_{j}$ : Typical activity for sector $\mathrm{j}$ (value added for industrial, commercial and transportation; number of households for residential); and

D: Demographic factor (Population or Urban 1 or Urban 2).

Foreshortening equation (2) by replacing $\frac{E_{i}}{E_{j}}=M_{i j}, \frac{E_{j}}{A_{j}}=I_{j}, \frac{V A_{j}}{D}=A_{j}$ we have equation (3):

$$
E_{j}=\sum_{i} M_{i j} \times I_{j} \times A_{j} \times D
$$

To separate the effect of each of the factors, we calculate the change of energy consumption between years 0 and $\mathrm{T}$ following each component by using a logarithmic mean function $\mathrm{L}(\mathrm{a}, \mathrm{b})=(\mathrm{a}-\mathrm{b}) /(\ln \mathrm{a}-\ln \mathrm{b})$. As a result, the final decomposition function is carried out in equation (4):

$$
\Delta E_{j}=\Delta E_{\text {mix }, i j}+\Delta E_{i n t, j}+\Delta E_{a c t, j}+\Delta E_{D, j}+\Delta E_{r s d, j}
$$

with:

- $\Delta E_{m i x}=\sum_{i} L\left(E_{i}^{t}, E_{i}^{0}\right) \ln \left(\frac{M_{i j}^{t}}{M_{i j}^{0}}\right)-$ Energy mix effect: the change in the aggregate associated with a change in the mix of energy used type;

- $\Delta E_{\text {int }}=\sum_{j} L\left(E_{i}^{t}, E_{i}^{0}\right) \ln \left(\frac{I_{j}^{t}}{I_{j}^{0}}\right)-$ Intensity effect: the change in the aggregate associated with changes in the energy intensities;

- $\Delta E_{a c t}=\sum_{i} L\left(E_{i}^{t}, E_{i}^{0}\right) \ln \left(\frac{A_{j}^{t}}{A_{j}^{0}}\right)-$ Activity effect: the change in the aggregate associated with a change in the overall level of the activity; 
- $\Delta E_{D}=\sum_{j} L\left(E_{i}^{t}, E_{i}^{0}\right) \ln \left(\frac{D_{t}}{D_{0}}\right)-$ Demographic effect: the change in the aggregate associated with a change in demographic factor; and

- $\Delta E_{r s d}-$ Residual term.

ASEAN urbanization effects on energy

The cumulative effect's formula is therefore:

$$
\Delta E=\sum_{j} \Delta E_{j}=\sum_{j} \Delta E_{m i x, i j}+\sum_{j} \Delta E_{\text {int }, j}+\sum_{j} \Delta E_{a c t, j}+\sum_{j} \Delta E_{D, j}+\sum_{j} \Delta E_{r s d, j}
$$

where $\Sigma_{j} \Delta E_{j}$ is the total of the change of energy consumption between years 0 and $\mathrm{T}$ in sector j.

In a second approach, this paper implements the same method for the country calculation with an additional factor that is the economic structural factor. Therefore, it is capable of comparing each factor's change between sectorial and national levels. To estimate the effect of the shift in the mix of products (production structural effect), the article proposes adjusting the calculation to eliminate residential energy consumption from total energy consumption. Thus, the final effects in this case reflect the ratio of the final energy use of three sectors including commercial, industrial and transportation sectors.

The formulas are converted to equation (6):

$$
E_{j} \sum_{i} \frac{E_{i j}}{E_{j}} \times \frac{E_{j}}{V A_{j}} \times \frac{V A_{j}}{\sum_{j} V A_{j}} \times \frac{\sum_{j} V A_{j}}{D} \times D
$$

Foreshortening equation (6) by replacing $\frac{E_{i}}{E_{j}}=M_{i j}, \frac{E_{j}}{V A_{j}}=I_{j}, \frac{V A_{j}}{\sum_{j} V A_{j}}=S_{j}, \frac{\sum_{j} V A_{j}}{D}=A_{j}$ we have equation (7):

$$
E_{j}=\sum_{i} M_{i j} \times I_{j} \times S_{j} \times A_{j} \times D
$$

The cumulative effect is calculated following equation (8)

$$
\Delta E=\Delta E_{\text {mix }, i j}+\Delta E_{\text {int }, j}+\Delta E_{s t r, j}+\Delta E_{a c t, j}+\Delta E_{D}+\Delta E_{r s d}
$$

With:

- $\Delta E_{m i x}=\sum_{i} L\left(E_{i}^{t}, E_{i}^{0}\right) \ln \left(\frac{M_{i j}^{t}}{M_{i j}^{0}}\right)$ - energy mix effect: the change in the aggregate associated with a change in the mix of energy used type;

- $\Delta E_{i n t}=\sum_{i j} L\left(E_{i j}^{t}, E_{i j}^{0}\right) \ln \left(\frac{I_{i}^{t}}{I_{i}^{0}}\right)$ - intensity effect: the change in the aggregate associated with changes in the energy intensities;

- $\Delta E_{s t r}=\sum_{i j} L\left(E_{i j}^{t}, E_{i j}^{0}\right) \ln \left(\frac{S_{i}^{t}}{S_{i}^{0}}\right)$ - economic structure effect: the change in the aggregate associated with a change in the mix of the activity by sub-sector; 
- $\Delta E_{a c t}=\sum_{i j} L\left(E_{i j}^{t}, E_{i j}^{0}\right) n\left(\frac{A_{j}^{t}}{A_{j}^{0}}\right)$ - activity effect: the change in the aggregate associated with a change in total value added per capita;

- $\Delta E_{D}=\sum_{i j} L\left(E_{i j}^{t}, E_{i j}^{0}\right) n\left(\frac{D_{t}}{D_{0}}\right)$ - demographic effect: the change in the aggregate associated with a change in demographic factor.

- $\Delta E_{r s d}-$ Residual term

This paper considers different demographic factors including population and two urbanization indicators to compare their contributions to energy consumption changes among the different factors. The first urbanization indicator is the total population living in urban areas, named Urban 1, reflecting the general rural-urban migration. The second is the number of non-agriculture employees in the total workforce, named Urban 2 , representing the effect of urban pull factors with industrialization and urban-biased policies.

\subsection{Data selection}

The study is based on multi-country and cross-sectoral data for the period 1995-2013. The demographic data are collected from the World Bank database. Energy consumption is divided into whole consumption and sectorial consumption as well as into fuel energy, renewable energy and electricity. It is collected from the International Energy Agency (IEA 2016) database.

GDP data is collected by cross-country and cross-sectional data. The panel data covers the value-added contribution of all major economic sectors consisting of commercial, industrial, and transportation, and the GDP of the whole economy is summed up from the Asian Development Bank (2015) source. The dataset is validated between alternative sources such as The World Bank (2015), Asian Development Bank (2015) and International Monetary Fund (2015).

Particularly for the residential sector, this paper suggests considering the number of households as an activity indicator. This data is summarized from annual national population reports. Some missing data is encountered, which is accounted for by linear interpolation, see Table I for details.

Missing data is a problem in some countries such as Singapore and Laos, and leads to incalculable results. Moreover, the inconsistency in collecting data in Indonesia when combining value-added from transportation with commercial value-added made it impossible to compare the results with other countries. Therefore, this paper only presents the results for 7 countries, consisting of 1 high-income country (Brunei), two upper-middle-income countries (Malaysia and Thailand) and four low-middle-income countries (Cambodia, Myanmar, the Philippines and Vietnam).

Table I.

Summary of the data set and their sources

\begin{tabular}{llll}
\hline Sector & Activity & Energy data & Demographic \\
\hline Residential & $\begin{array}{l}\text { Number of households - National } \\
\text { population censuses report }\end{array}$ & $\begin{array}{l}\text { Fuel, renewable, } \\
\text { electricity - IEA }\end{array}$ & World Bank \\
Commercial & Added value, GDP - World Bank & 2015 & \\
$\begin{array}{l}\text { Industrial } \\
\text { Transportation }\end{array}$ & 2015 and ADB database 2015 & Fuel - IEA 2015 & \\
\hline
\end{tabular}




\section{Results}

The empirical analysis is conducted by comparing the impact of the energy mix, energy intensity, activity, structure, and three demographic indicators (Population, Urban 1, and Urban 2) on the energy consumption in ASEAN during 1995-2013. Overall results are shown in Tables II and III for the approach without and with the economic structure indicator. In general, energy consumption growth in ASEAN countries is mostly caused by demographic and economic changes. Energy mix contributed positively but insignificantly. Meanwhile, energy intensity is the only factor continuously supporting energy consumption reductions (see Tables II and III).

Without the economic structure approach, demographic effects are the strongest drivers of energy consumption growth in ASEAN from 1995 to 2013, especially from the 2000s (see Figure 4), with average contributions of around 30-70 per cent, 60-150 per cent and 60-240 per cent for population, Urban 1 and Urban 2 respectively (see Table II). Exceptional contributions occur in the Philippines and are discussed in detail in Section 5. With the economic structure approach, production growth is revealed as the strongest driver instead of the demographic effects (see Table III).

For country comparisons, the demographic effect of population change influence on energy consumption is wieghted at 1 , thus providing a basis for comparison of the three demographic indicators Population, Urban 1, and Urban 2 across countries and sectors (see Tables IV and V). For example, overall the Urban 1 and Urban 2 effects are on average 1.8 and 2.7 times stronger than the population effects on total energy consumption in all considered countries (Table IV). For individual countries, Urban 1 and Urban 2 have a

\begin{tabular}{|c|c|c|c|c|c|c|c|c|}
\hline Country & $\begin{array}{l}\text { Energy } \\
\operatorname{mix}\end{array}$ & $\begin{array}{l}\text { Energy } \\
\text { intensity }\end{array}$ & $\begin{array}{c}\text { Economic- } \\
\text { Population case }\end{array}$ & $\begin{array}{l}\text { Economic- } \\
\text { Urban } 1 \text { case }\end{array}$ & $\begin{array}{l}\text { Economic- } \\
\text { Urban } 2 \text { case }\end{array}$ & Population & $\begin{array}{c}\text { Urban } \\
1\end{array}$ & $\begin{array}{c}\text { Urban } \\
2\end{array}$ \\
\hline Brunei & 0.48 & -25.49 & 57.40 & 35.14 & 30.61 & 67.62 & 89.88 & 94.41 \\
\hline Cambodia & 0.50 & -35.81 & 67.22 & 34.43 & -105.37 & 68.09 & 100.88 & 240.68 \\
\hline Malaysia & 0.34 & -5.49 & 67.39 & 36.83 & 46.49 & 37.77 & 68.33 & 58.66 \\
\hline Myanmar & 0.19 & -100.04 & 131.69 & 47.27 & -32.42 & 68.16 & 152.57 & 232.26 \\
\hline Philippines & 1.17 & -1235.80 & 815.90 & 911.24 & 366.17 & 520.61 & 425.27 & 970.34 \\
\hline Thailand & 0.14 & -0.39 & 66.56 & -15.69 & -8.55 & 33.69 & 115.94 & 108.80 \\
\hline Vietnam & 2.06 & -49.16 & 123.32 & 85.93 & 36.18 & 23.78 & 61.16 & 110.92 \\
\hline
\end{tabular}

Note: Unit: \%/a

\section{ASEAN urbanization effects on energy}

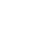




\section{IJESM}

Figure 4.

The impact of Urban 1 in relation to other impacts on energy consumption changes in seven ASEAN countries from 1995 to 2013 by decomposed economic effect approach
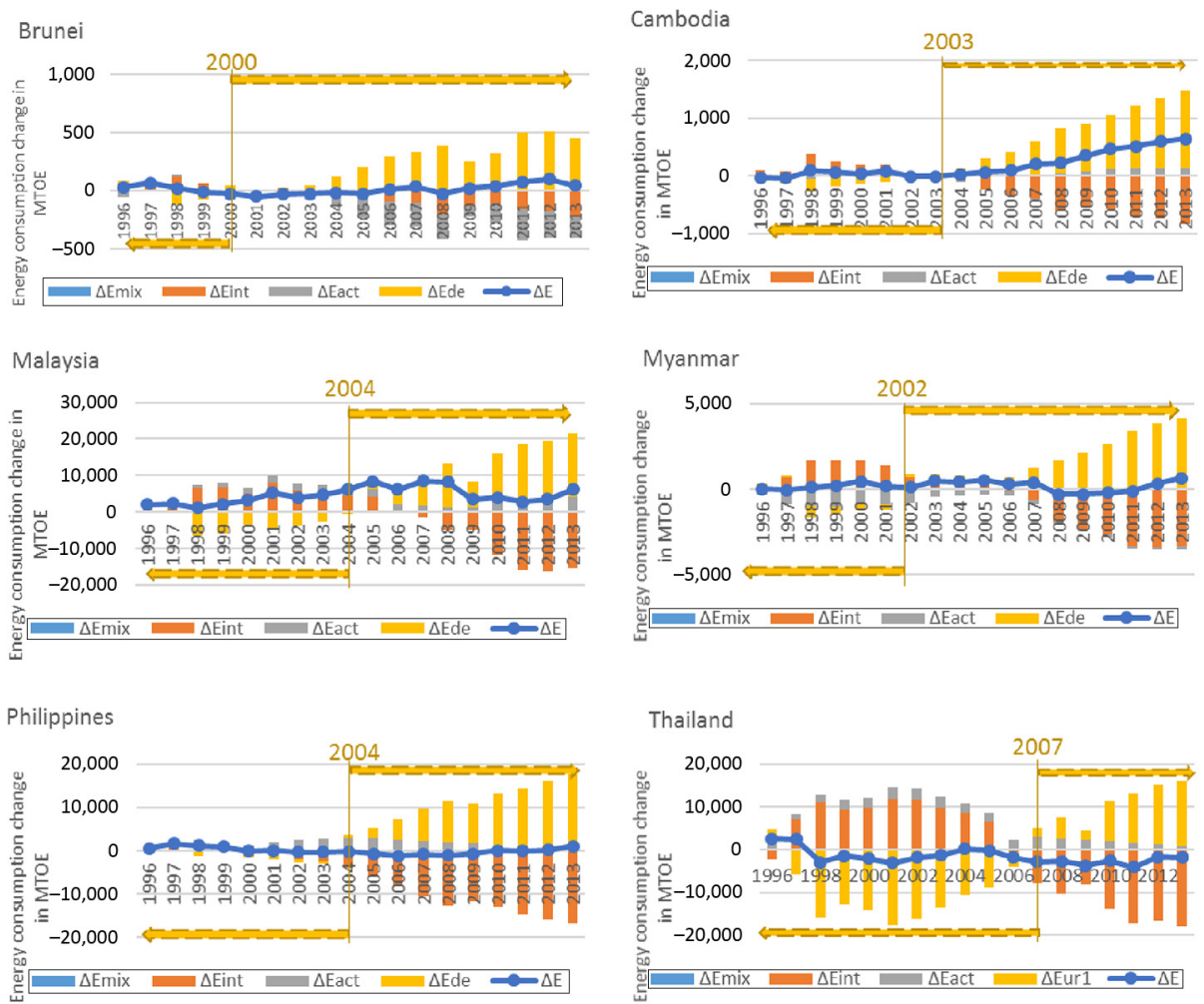

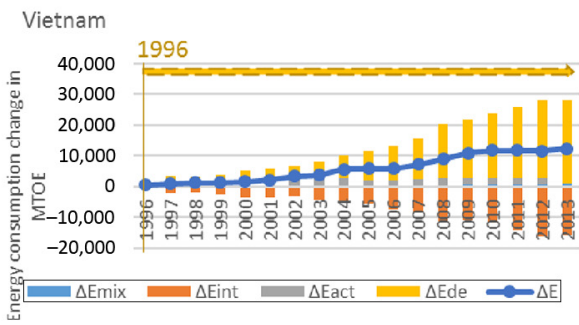

Note: The milestone marks the transition from decreasing to increasing energy consumption of Urban 1

relatively equal influence in Brunei, Malaysia and Thailand. But Urban 2 is significantly stronger than Urban 1 in the other countries (Table V).

For sectorial comparison and cross country-sector comparisons, the demographic effect of population change influence on commercial energy consumption is weighted at 1. Tables VI and VII respectively describe the demographic effect on energy consumption changes across sector and country over the past two decades, relative to this value of unity. Out of all sectors in all cases, Urban 2 or non-agricultural workers ranked highest in industrial and residential sectors with 13.21 and 15.12 respectively 
(Table VI). The Urban 1 factor affects most strongly the residential energy consumption in the case of the cumulative economic effect at 8.69, and in transportation in case of the decomposed economic effect at 6.86. Exceptional cases are recorded in Malaysia and Thailand, where Urban 1 impacts stronger than Urban 2, and in the Philippines where the Urban 1 has less influence than population and Urban 2 (Table VII).

Figure 5 provides an assessment of the scaled impact of demographic factors on energy consumption in the 7 analyzed ASEAN countries. This figure describes the relevance of demographic size and its impact on total energy consumption changes. The size of the circles shows the strength of the respective demographic effects (Urban 1, Urban 2, population) over the whole period and the y-axis shows the average annual rate of change. The $\mathrm{x}$-axis is arranged in order of increasing income. The figure clearly illustrates the three different groups of countries according to their income level. In the lower-middle-income group the Urban 2 effect is strongest, followed by Urban 1 and Population, with

\begin{tabular}{lccc}
\hline Overall & Population & Urban 1 & Urban 2 \\
\hline Without economic structure concern & 1.00 & 1.82 & 2.80 \\
With economic structure concern & 1.00 & 1.84 & 2.54 \\
\hline
\end{tabular}

\section{ASEAN urbanization effects on energy}

Table IV.

The overall comparison of demographic factors impact on energy consumption change in ASEAN in the period 1995-2013 $($ population $=1)$

\begin{tabular}{|c|c|c|c|c|}
\hline Country & Population & Urban 1 & Urban 2 & Table V. \\
\hline Brunei Darussalam & 1.00 & 1.33 & 1.40 & $\begin{array}{l}\text { Comparison of } \\
\text { demographic factors }\end{array}$ \\
\hline Cambodia & 1.00 & 1.48 & 3.53 & demograpnic ractors \\
\hline Malaysia & 1.00 & 1.81 & 1.55 & impact on energy \\
\hline Myanmar & 1.00 & 2.24 & 3.41 & consumption growth \\
\hline Philippines & 1.00 & 0.82 & 1.86 & by country in the \\
\hline Thailand & 1.00 & 3.49 & 3.25 & period $1995-2013$ \\
\hline Vietnam & 1.00 & 2.57 & 4.66 & $($ population $=1)$ \\
\hline
\end{tabular}

\begin{tabular}{|c|c|c|c|c|c|}
\hline Urban indicator & $\mathrm{COM}$ & IND & RES & TRA & Table VI. \\
\hline \multicolumn{5}{|c|}{ Without economic structure concern } & rall sectorle \\
\hline Population & 1.00 & 6.50 & 5.48 & 5.28 & comparison of \\
\hline Urban 1 & 1.99 & 7.45 & 8.69 & 7.39 & demographic factors \\
\hline Urban 2 & 2.85 & 13.21 & 15.12 & 10.99 & impact on energy \\
\hline \multicolumn{5}{|c|}{ With economic structure concern } & $\begin{array}{l}\text { consumption growth } \\
\text { in ASEAN in the }\end{array}$ \\
\hline Population & 1.00 & 5.66 & & 4.91 & in ASEAN in the \\
\hline Urban 1 & 1.73 & 6.41 & & 6.86 & period 1995-2013 \\
\hline Urban 2 & 2.51 & 11.69 & & 10.29 & (population in \\
\hline \multicolumn{5}{|c|}{ Notes: Acronyms: COM - commercial; IND - industrial; RES - residential; TRA - transportation } & sector $=1)$ \\
\hline
\end{tabular}




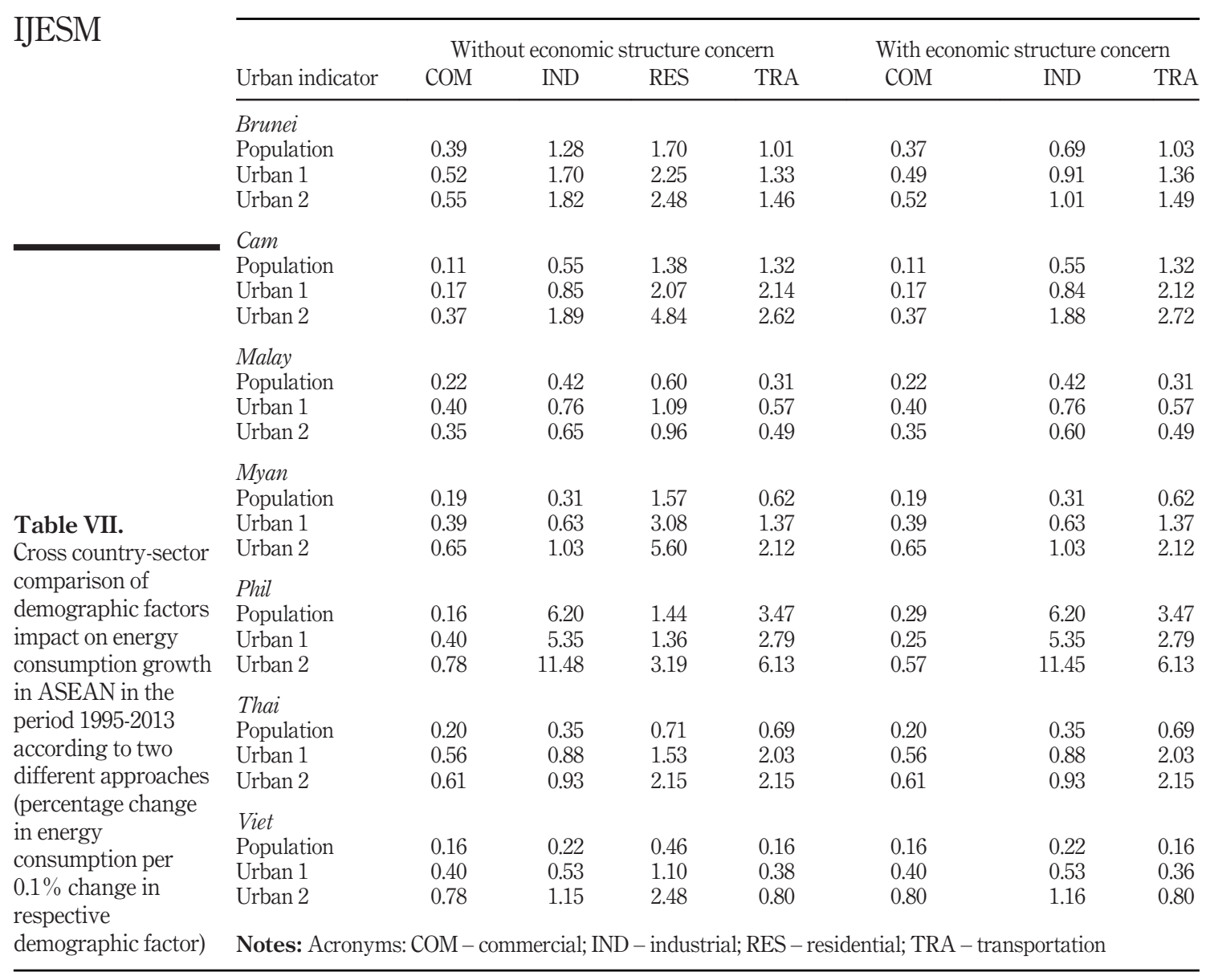

the exception of the Philippines (see next section). The upper-middle-income group is characterised by higher Urban 1 effects, followed by Urban 2 and Population. The third group, high income countries, shows similar effects of both Urban 1 and 2, both stronger than the Population effect.

The overall influence of the different demographic factors on each sectorial energy consumption in the 7 countries is presented in Figure 6. The sectors are shown in turn from left to right including commercial, industrial, and residential sectors and transportation. The vertical axis represents the impact of the demographic factor on the relative sectorial energy consumption changes, in dimensionless units of percentage change of the energy consumption per 1 per cent change in Urban 1. The rectangular boxes show the upper and lower quartiles of the data, the whiskers outside the box indicate the spread outside these quartiles, and the circular points show outliers. In general, changes in both urban dwellers (Urban 1) and employees in the non-agricultural field (Urban 2) made the largest contribution to increasing energy consumption in households. The influence seems to be smaller for the transportation and industrial sectors and very small for the commercial 


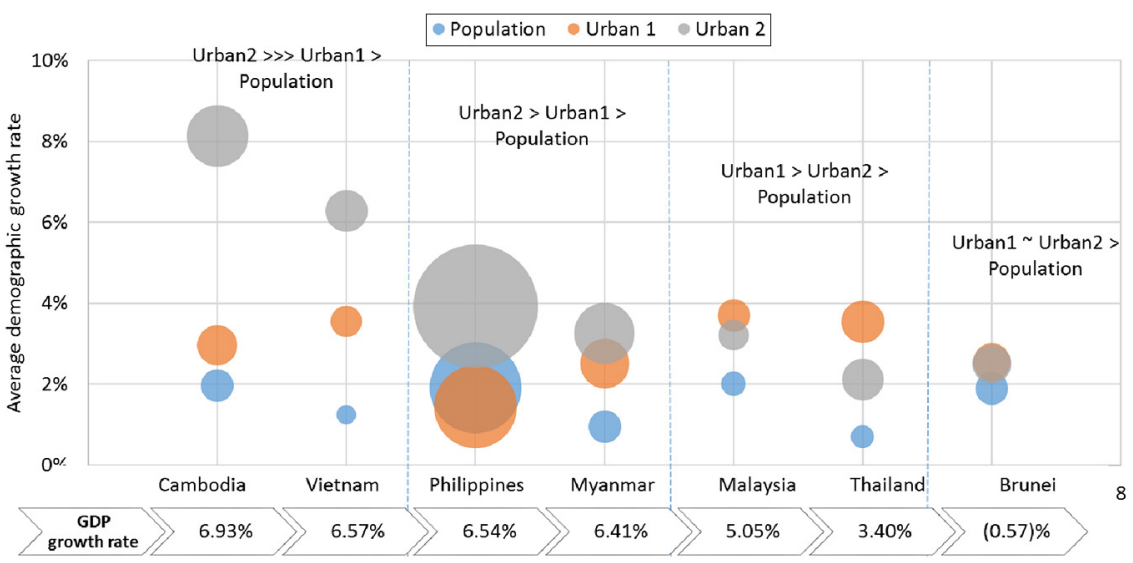

Notes: X-axis: considered countries corresponding with their factors divided into four groups. Y-axis: average demographic growth rate including population, Urban 1 and Urban 2. Bubble size: the level of demographic factor impact on energy consumption by each factor in each country

\section{ASEAN urbanization effects on energy}

Figure 5.

Cross-country comparison of impact levels by different demographic factors on energy consumption growth in 7 ASEAN countries from 1995 to 2013

1. Residential > Transportation > Industrial > Commercial
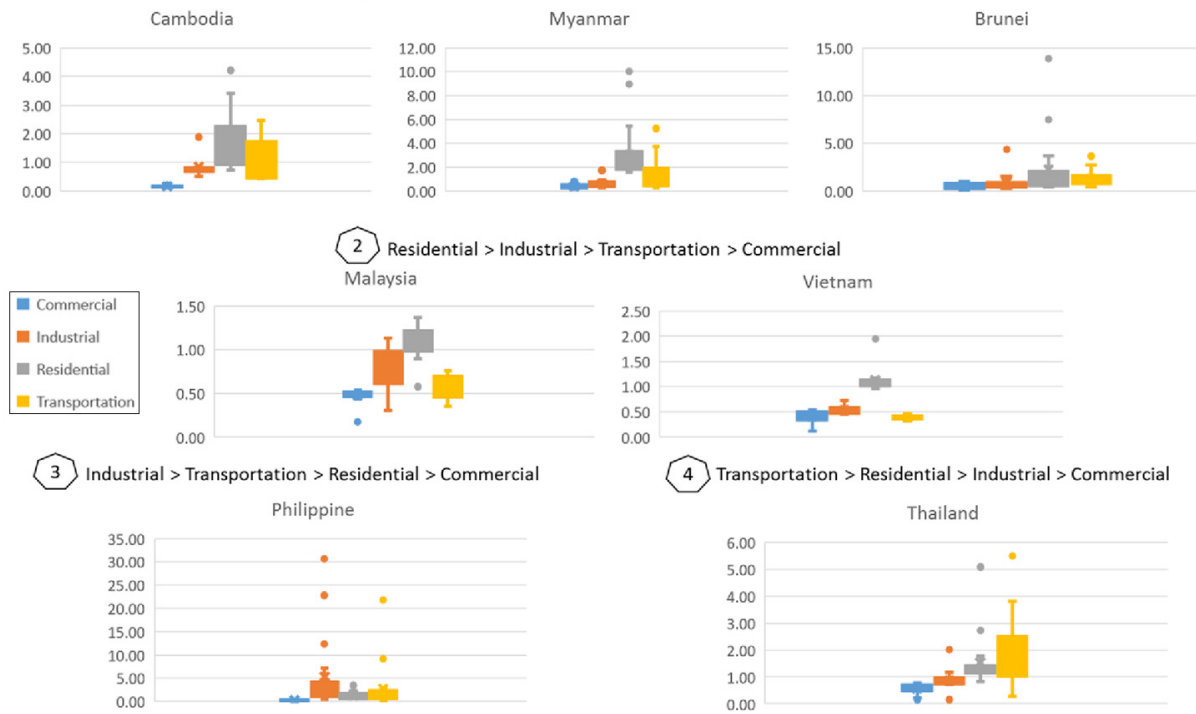

Note: Percentage change in respective effect per 1\% change in Urban 1 indicator

Figure 6. Groups of different annual average effects of Urban 1 on sectors in the 7 ASEAN countries from 1995 to 2013 


\section{IJESM}

\section{Figure 7.}

Fossil fuel share in TPES (own calculation based on database of IEA, 2015) and the energy mix effect share in TPES changes from 1995 to 2013 in seven ASEAN countries sector. Detailed results for each sector per year during the considered period can be seen in Table VII.

\section{Discussion and policy implications}

In this section, we discuss our main results and the applied method. The first section focusses on the effects of urbanization on the energy mix, in the context of the question whether urbanization could promote the energy transition. The second section then examines which factors policies are required to consider, to ensure sustainable development. The third section highlights the different impacts of urbanization on energy consumption, according to the income level of the country. The subsequent sections present a sensitivity analysis and critically discuss the method, respectively.

\subsection{The correlation between urbanization, energy mix and energy consumption effects, and the example of the Philippines}

The decomposition results show that the energy mix effect contribution to the energy changes is generally quite weak, with from 0.1 per cent to 3 per cent (with the exception of the Philippines, discussed below) from 1995 to 2013 (Tables II, III and Figure 7). Despite the extensive government efforts to encourage renewable energy development through national energy policies, the regional reliance on fossil fuels is increasing with an average annual growth rate at 0.8 per cent during the considered period (Figure 7 ). The results also show that the transition rate from fossil fuels to electricity and renewable energy is happening even more slowly in the considered countries, with an average annual growth rate of 0.35 per cent from 1996 to 2004 compared with a rate of - 0.11 per cent from 2005 to 2013 (Figure 7). The decrease is mainly due to the increase in using fossil fuel within the industrial and residential sectors. This could be evidence that the swelling population in cities and industrialization is putting pressure on the region's energy security.

The exception here is the Philippines with a negative impact of the energy mix recorded during the period of 2006 to 2010 (Figure 7). A deeper look at the energy mix impacts by sectors (Figure 8) reveals that these negative values are caused by the dramatic reduction in the residential sector in the Philippines during the 18 studied years, with an average decreasing rate of 1.7 per cent per year. The energy consumption in the residential sector in the Philippines counteracts positive effects in other sectors, thus accounting for the overall negative energy mix effect seen across the entire economy.

The successful strategy in dealing with urbanization in the Philippines could be seen as a positive example to counter increasing energy demand. Since the urbanization crisis became a concern of the Government in the 2000s, the Philippines has played a key role in the global debate on sustainable urbanization. As an active member on Human Settlements or Habitat 
II, the Philippines' commitments on infrastructure development have made significant achievements after 20 years[3], by effectively reducing the rapid rate of urbanization growth. Thereby, it successfully limited the urbanization effect on energy consumption to remain even smaller than the population effect (Figure 5). Since 2016, under the auspices of the Habitat III[4] process, this may enable the Philippines to further reduce the urbanization effect on energy consumption as well as providing a good practice example for other countries.

\subsection{The focus of ASEAN energy policy}

Among the studied demographic influences, the urbanization factors generally exhibit a stronger effect on energy demand increases than population in the region (with the exception of the Philippines, Table V and Figure 5). After 1990, along with economic development, ASEAN entered a period of rapid urban population growth (Urban 1), which rose to an average of 3.2 per cent per year (World Bank, 2018). However, after more than 10 years of increasing, since the 2000s, Urban 1 has started to put pressure on energy consumption in ASEANs. It started in Brunei, which has the highest rate of urbanization, in 2000 and then spread all over ASEAN. Vietnam has been affected since 1995, but the effect has become relatively strong since 2004 (Figure 4).

Moreover, ASEAN economies are likely to expand at a rapid pace and have attained high rates of Urban 2 - non-agriculture employment growth. Consequently, Urban 2, which reflects the growth in industrial development in this region, is the strongest effect among the demographic indicators (Tables V and VI).

The results show that, if Urban 1 and Urban 2 would increase by only 0.1 per cent, it will require an energy demand increase by on average 1.44 per cent and 2.59 per cent respectively (Tables II and III). Urbanization is leading to rapidly increasing domestic energy demand, especially in Cambodia, Myanmar and Vietnam (Figure 9), followed by significant growth in industry and transport (ASEAN as a whole in Table VI and detailed by country in Table VII and Figure 9). The urbanization effect on transportation is gradually becoming stronger than on industry, especially in Thailand (Figure 9).

Facing the urbanization challenge, this paper provides an estimation for the energy consumption change in each sector of each considered country corresponding to 0.1 per cent urbanization changes (Table VII). It reveals the potential that controlling urbanization could reduce the pressure on energy supply. For example, Urban 1 in Vietnam is 34 per cent, which indicates that around 32 million people are living in urban areas. Based on the estimation, if the government could avoid 0.1 per cent in Urban 1 increase (meaning 32,000

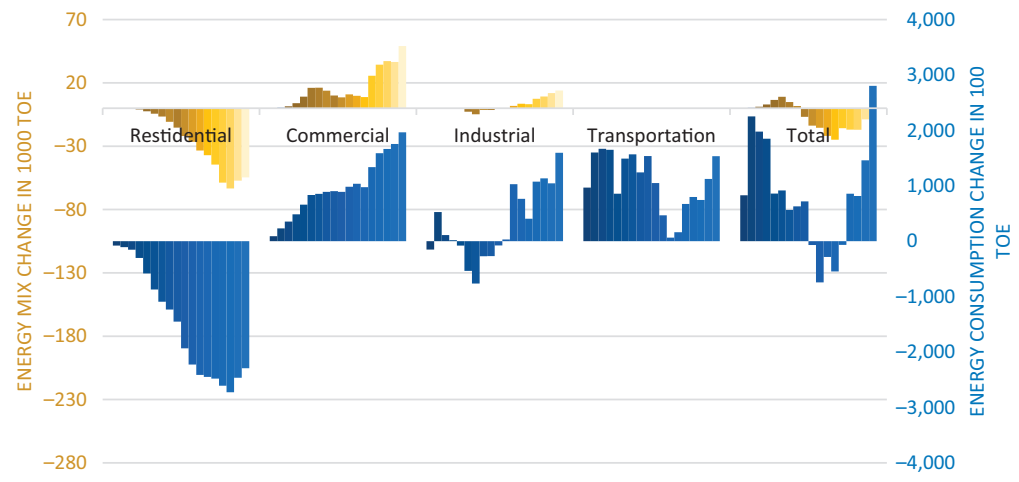

\section{ASEAN urbanization effects on energy}




\section{IJESM}

\section{Figure 9.}

Cross country-sector comparison of urbanization effects on energy consumption growth in seven ASEAN countries between 1995 and 2013

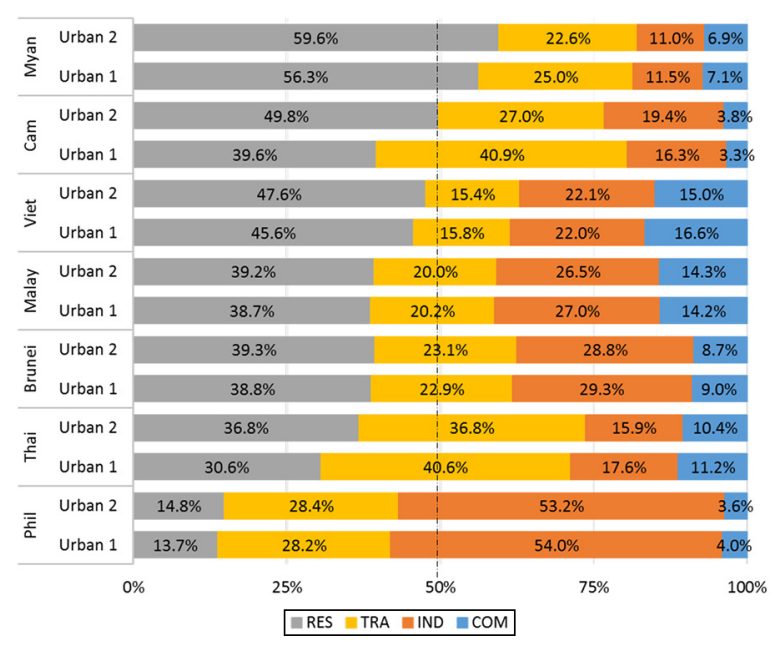

Notes: Acronyms: RES - residential, TRA - transportation, IND - industrial, COM - commercial

people) per year, it could help to avoid 0.4 per cent, 0.53 per cent, 1,1 per cent and 0.38 per cent energy demand increases in the commercial, industrial, residential and transportation sectors respectively. The results could be used as a reference for policy makers to integrate energy policy with urban and economic plans.

Because urbanization, and not population, is one of the main drivers for increasing energy consumption and is concentrated in the residential sector, there is an obvious need for specific energy policy at the regional and city levels. It is beyond the remit of government agencies to coordinate among all local bodies and conduct comprehensive policy analysis and performance evaluation, because of lacking capacity and resources at the national level. In addition, responsibility in energy policy, planning and implementation at the city level could be fragmented and contradictory, compared to the respective current sub-sector energy policy. This lack of attention and capacity from national institutions to subnational energy policy could present an opportunity for regional and local organizations. However, city-level decision makers at least need signals and guidelines from the national level to develop effective policies, and the state has to coordinate these activities as much as is feasible. This includes ensuring that local policymakers can effectively engage with stakeholders at all levels and that local experiences with new policies are considered in the national context.

\subsection{Insights for countries' income-levels on urbanization and energy consumption}

This paper analyzed the two urbanization indicators including Urban 1 (urban population in urban areas) and Urban 2 (non-agricultural employment), which represents industrialization, to investigate the difference between the two indicators on energy consumption. The results show there are three typical groups (Figure 5), which are closely linked to the national income levels: 
- Group 1 as Brunei - high-income country (based on World Development Indicators, World Bank data, 2016) where Urban 1 and Urban 2 have similar effects on energy consumption growth.

- Group 2 including Malaysia and Thailand, upper middle-income countries, where Urban 1 is stronger than Urban 2.

- Group 3 including Cambodia, Myanmar, Philippines and Vietnam, lower middleincome countries, where Urban 2 has stronger effect on energy consumption growth than Urban 1.

Thus, it can be seen that, the lower income the country is, the stronger urbanization and industrialization effect energy consumption growth. In other words, lower-income countries are more severely affected by urbanization in increasing energy consumption. Accordingly, the demand for urban management in the context of energy consumption growth in these countries becomes more urgent and the policy development process needs to consider this fact. For example, the high-income countries exhibit effects based on all three factors that are very similar (Figure 5), hence little or no specific urbanization policy is required. The upper-middle-income countries, on the other hand, exhibit strong urbanization according to Urban 1, therefore need effective policies to manage this process and should look to the Philippines for inspiration. The lower-middle-income countries have a much stronger industrialization effect (Urban 2), and therefore need to focus attention on effective policies to manage this rapid change alongside energy demand increases. Whilst the three remaining ASEAN countries were not included in the analysis because of a lack of data, these broad policy insights could also be generalized towards them (i.e. high-income: Singapore, lowermiddle-income: Laos PDR, and upper-middle-income: Indonesia).

\subsection{Sensitivity analysis}

This study analyzed the robustness of the results in the presence of uncertainties. The calculated data units and the estimated percentage statistical errors of each variable are listed in Table VIII.

The statistical errors in Table VIII are estimated by comparing different data resources. To calculate the statistical errors in GDP data, this paper determined the difference in percentage in the same referred time and currency between two data sources including the World Bank database 2018 and the ADB database 2015. The statistical errors of population, Urban 1 and Urban 2 are estimated by comparing between the World Bank database 2018, the ADB database 2015 and the IMF database 2015. The results show that the difference between them is around 0.01 per cent to 0.2 per cent respectively. On the other hand, the energy statistical errors from the IEA database represent the amount by which an observation differs from itself, before and after the IEA revises the data every year when they update the database.

To account for the case of unknown statistical errors, the paper varies the input values within the range of \pm 50 per cent for given input parameters such as demographics, activity

\begin{tabular}{llcr}
\hline Variable & Data units & Statistical errors & \\
\hline Demographic & Billion people & $0.01-0.2$ & Table VIII. \\
GDP & Billion \$ & $0.01-0.2$ & Analysis of the \\
Energy & 1000 TOE & $0.1-7$ & statistical errors \\
\hline
\end{tabular}




\section{IJESM}

and energy consumption. Figure 10 shows that, for every 1 per cent variation in the input, the activity effect will change by around -5.5 per cent and the demographic effect would change by 5.5 per cent. However, it will not affect the energy intensity effect. Similarly, if the activity value changes, every 1 per cent of this will cause energy intensity effect changes of 5.5 per cent and activity effect changes of -5.5 per cent, but this has no impact on the demographic effect.

Furthermore, every 1 per cent error in the energy consumption statistics could cause a 1 per cent change in the energy intensity effect, a -0.5 per cent change in activity effect and a -0.6 per cent error in the demographic effect. The results also show the limitation of the decomposition method, especially for the logarithmic mean divisia index (LMDI). It has trouble dealing with zero values so the results can give an incorrect value. For example, in this case this effect occurs at the point of a 20-25 per cent negative change in the energy consumption.

\subsection{Critique of the decomposition method in analyzing the relationship between energy and urbanization}

This section discusses the strengths and limitations within the study. Regression may produce unreliable results in describing the relationship between energy consumption and other factors. For example, in the case of Brunei, the $r$-squared is relatively low, around 6 per cent and 16 per cent in the case of analyzing the relationship between energy consumption and GDP, Urban 1 respectively (Figure 11). The decomposition method does not encounter many obstacles in comparing the correlation between variables (Figure 12). Thus, it is an alternative approach to analyze the relationship between energy consumption and urbanization. The decomposition is also superior to regression in case of horizontal (crosscountry) and vertical (cross-sector) comparisons.

However, the decomposition method also has its disadvantages, which are the process of collecting and synchronizing data, choosing the appropriate decomposition analysis method, problems associated with considering new variables (e.g. population and urbanization factors), and the errors resulting from a zero difference between the value in two considered periods. The data capable for computing needs to be collected with the same

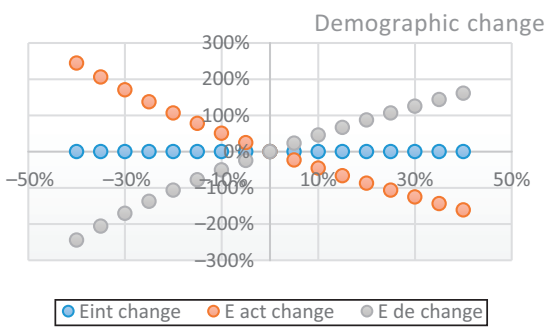

Figure 10.

The results of the sensitivity analysis for selected variables -Unit: \%

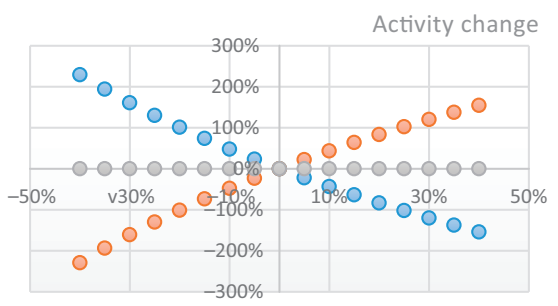




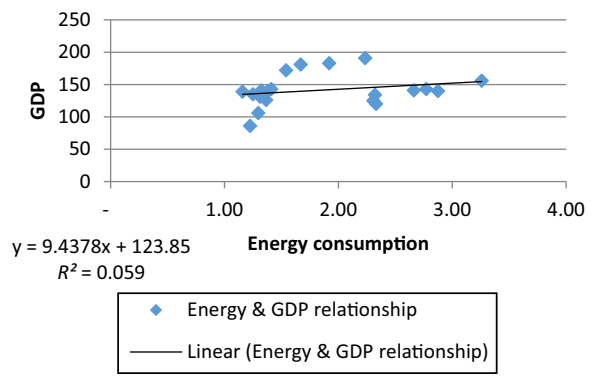

\section{ASEAN urbanization effects on energy}

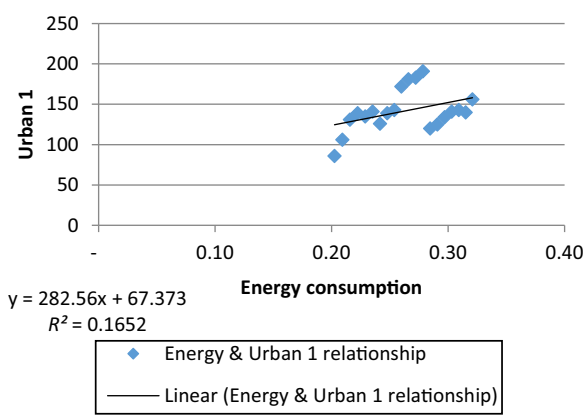

Figure 11.

Notes: Unit: GDP: million USD 2005, Urban: million people, Energy consumption: 1,000 TOE

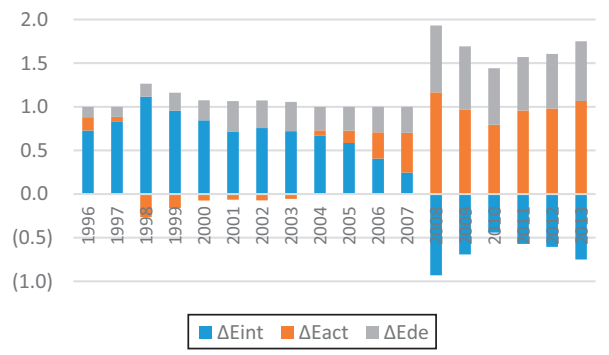

Figure 12. The results of relation analysis for selected variables by using decomposition in Brunei with cumulative economic approach - Unit: 100 MTOE

reference year and statistical method in all countries. Therefore, the end-use database is calculated and synchronized with the reference year as 1995. Moreover, the zero problem was handled following the suggestion of Ang and Liu (2007) by replacing with $\partial$, where $\partial<10^{-20}$.

Finally, the decomposition method describes a relative comparison between variables instead of considering the dependence of different variables. It can therefore provide the correlation of different effects on one or several variables; however, it cannot determine an exact weight representing the level of influence. Hence, the choice of appropriate method always depends on the application and should be made with the above issues in mind. 


\section{Conclusion and outlook}

The essential requirement of restraining energy consumption and promoting energy efficiency is becoming more important in the context of economic and urban growth. The first priority of ASEAN governments should therefore be to identify factors that have an effect on energy consumption and developing appropriate policies. A deeper analysis of the disaggregate results for each sector and country enables a more accurate understanding of the urban impacts on energy consumption.

With this purpose, the decomposition method has been implemented in this paper for seven ASEAN countries from 1995 to 2013 to assess the effects of urbanization on energy consumption and compare this effect based on multi-level indicators. This analysis is based on two types of urbanization, including the general urban indicator of urban population and the pull urban indicator of non-agriculture workers. The results decompose the changes of overall energy consumption into intra- and international effects and isolate the contribution of each component factor including energy mix, energy intensity, activity, and urbanization. To the authors' knowledge, this is a novelty, as previous studies have only shown results across sectors or countries.

While there was some controversy about the effect of urbanization on total energy consumption as well as sectorial energy consumption, this paper demonstrates the positive effect of urbanization at national and sectorial levels in the ASEAN region. Although effects are different among the countries, the urbanization effect on energy consumption is stronger in lower income countries. The results show that the effect of urbanization factors is much more significant than the population effect and the other effects including energy intensity and activity in the whole country, as well as in each of the sectors in the region.

The detailed results about urbanization-related energy consumption changes in Table VII could serve as a suggestion for the whole ASEAN region in controlling urbanization and its effects on energy consumption. The strong effect of urbanization on domestic energy consumption poses new questions for policy makers in this field. In particular, they should focus efforts on finding an optimal solution to decentralized, efficient energy systems for current and future urban cities, especially in the commercial and household sectors. Therefore, the paper suggests three key recommendations to policy-makers in setting energy policy: (1) urban areas should be considered as one of the core targets for energy policy; (2) the lower-middle-income countries should pay attention to effective policies to manage the rapid change of the non-agriculture workers' effect; and (3) there is an essential need for energy policy at city-levels besides subsector-levels.

Looking to the future, instead of using energy consumption to assess the impact of urbanization, energy intensity analyses could be implemented. These would require updated and improved databases, and should apply direct approaches, based on energy service demands, rather than the indirect decomposition approach adopted here. For example, a complete dataset should be built, consisting of different and more detailed factors such as housing area for households, commercial building area for the commercial sector, and freight of goods for transportation. Such a database would enable the underlying causes of the urbanization and energy phenomena highlighted here to be examined more closely. Researchers should approach this problem from diverse disciplines, to more fully understand the complex relationship between the urbanization process and the carbon cycle. Moreover, whilst this study was able to provide valuable insights into the relationship between urbanization and energy consumption at the sector level, across ASEAN, for a period of a few decades, future work should analyze these phenomena at the national level and below, as well as differentiating between energy carriers. 


\section{Notes}

1. Divided by income group, ASEAN has ten members in three groups: two high-income countries including Brunei Darussalam and Singapore, two upper-middle-income countries including Malaysia and Thailand and six lower-middle-income countries including Cambodia, Indonesia, Lao PDR, Myanmar, the Philippines and Vietnam (World Bank, 2018, last accessed 03.12.2018).

2. The "fixed effect" method is used to treat pooled cross-sectional and time series data. It means the model is calculated with one variable fixed and in a constant proportion across countries.

3. For more information about the Philippines achievements on urbanization programs under Habit II see: www.hudcc.gov.ph/HABITAT_III

4. Habitat III is the New Urban Agenda. It is the outcome of the action plans agreed upon at the Habitat III cities conference in Quito, Ecuador, in October 2016.

\section{References}

Ang, B.W. and Zhang, F.Q. (2000), "A survey of index decomposition analysis in energy and environmental studies”, Energy, Vol. 25 No. 12, pp. 1149-1176.

Ang, B.W. and Liu, N. (2007), "Handling zero values in the logarithmic mean divisia index decomposition approach", Energy Policy, Vol. 35 No. 1, pp. 238-246.

ASEAN Energy Outlook (2017), "ASEAN center for energy, the 5th ASEAN energy outlook 20152040", available at: www.aseanenergy.org/resources/the-5th-asean-energy-outlook/

Asian Development Bank (2015), "Key Indicators for Asia and the Pacific 2015”, available at: www.adb. org/publications/key-indicators-asia-and-pacific-2015

Economic outlook (2019), "OCED report: economic outlook for Southeast Asia, China and India 2019", OCED, Paris.

Elliott, R.J.R., Sun, P. and Zhu, T. (2014), Urbanization and Energy Intensity: A Province-Level Study for China, University of Birmingham - Department of Economics, Birmingham, pp. 14-15.

Ewing, R. and Rong, F. (2008), "The impact of urban form on US residential energy use”, Housing Policy Debate, Vol. 19 No. 1, pp. 1-30.

Fan, J., Zhang, Y.J. and Wang, B. (2017), "The impact of urbanization on residential energy consumption in China. An aggregated and disaggregated analysis", Renewable and Sustainable Energy Reviews, Vol. 75, pp. 220-233, doi: 10.1016/j.rser.2016.10.066.

Halicioglu, F. (2007), "Residential electricity demand dynamics in Turkey", Energy Economics, Vol. 29 No. 2, pp. 199-210.

Hoekstra, R. and van den Bergh, J.C.J.M. (2003), "Comparing structural decomposition analysis and index”, Energy Economics, Vol. 25 No. 1, pp. 39-64.

Holtedahl, P. and Joutz, F.L. (2004), "Residential electricity demand in Taiwan”, Energy Economics, Vol. 26 No. 2, pp. 201-224.

International Energy Agency (2015), "Statistics for 2015", available at: www.iea.org/statistics/ statisticssearch/report

Jones, D.W. (1989), "Urbanization and energy use in economic development", The Energy Journal, Vol. 10 No. 4.

Jones, D.W. (1991), "How urbanization affects energy-use in developing countries", Energy Policy, Vol. 19 No. 7, pp. 621-630.

Jones, D.W. (2004), "Urbanization and energy", Encyclopedia of Energy, Elsevier, Amsterdam, pp. 329-335. 
Khuong, P.M., McKenna, R. and Fichtner, W. (2019), "Analyzing drivers of renewable energy development in Southeast Asia countries with correlation and decomposition methods", Journal of Cleaner Production, Vol. 213 No. 213, pp. 710-722.

Lariviere, I. and Lafrance, G. (1999), "Modelling the electricity consumption of cities: effect of urban density", Energy Economics, Vol. 21, (PII: S0140 - 988398.00007-3).

Lenzen, M., Wier, M., Cohen, C., Hayami, H., Pachauri, S. and Schaeffer, R. (2006), "A comparative multivariate analysis of household energy requirements in Australia, Brazil, Denmark, India and Japan”, Energy, Vol. 31 Nos 2/3, pp. 181-207.

Li, B. and Yao, R. (2009), "Urbanisation and its impact on building energy consumption and efficiency in China”, Renewable Energy, Vol. 34 No. 9, pp. 1994-1998.

Liddle, B. and Lung, S. (2014), "Might electricity consumption cause urbanization instead? Evidence from heterogeneous panel long-run causality tests", Global Environmental Change, Vol. 24, pp. 42-51.

Liu, Y. (2009), "Exploring the relationship between urbanization and energy consumption in China using ARDL (autoregressive distributed lag) and FDM (factor decomposition model)", Energy, Vol. 34 No. 11, pp. 1846-1854.

Liu, H. and Lei, J. (2018), "The impacts of urbanization on Chinese households' energy consumption. An energy input-output analysis", Journal of Renewable and Sustainable Energy, Vol. 10 No. 1, p. 15903, doi: 10.1063/1.5020077.

Liu, Y. and Xie, Y. (2013), "Asymmetric adjustment of the dynamic relationship between energy intensity and urbanization in China”, Energy Economics, Vol. 36, pp. 43-54.

Madlener, R. and Sunak, Y. (2011), "Impacts of urbanization on urban structures and energy demand. What can we learn for urban energy planning and urbanization management?", Sustainable Cities and Society, Vol. 1 No. 1, pp. 45-53.

Mishra, V., Smyth, R. and Sharma, S. (2009), "The energy-GDP nexus. Evidence from a panel of Pacific Island countries", Resource and Energy Economics, Vol. 31 No. 3, pp. 210-220, doi: 10.1016/j. reseneeco.2009.04.002.

Pachauri, S. and Jiang, L. (2008), "The household energy transition in India and China”, Energy Policy, Vol. 36 No. 11, pp. 4022-4035.

Parikh, J. and Shukla, V. (1995), "Urbanization, energy use and greenhouse effects in economic development”, Global Environmental Change, Vol. 5 No. 2, pp. 87-103.

Poumanyvong, P. and Kaneko, S. (2010), "Does urbanization lead to less energy use and lower $\mathrm{CO}_{2}$ emissions? A cross-country analysis", Ecological Economics, Vol. 70 No. 2, pp. 434-444.

Poumanyvong, P., Kaneko, S. and Dhakal, S. (2012a), "Impacts of urbanization on national transport and road energy use: evidence from low, Middle and high income countries", Energy Policy, Vol. 46, pp. 268-277.

Poumanyvong, P., Kaneko, S. and Dhakal, S. (2012b), "Impacts of urbanization on national residential energy use and $\mathrm{CO} 2$ emissons. Evidence from low-, middle- and high-income countries", IDEC DP2 Series, Vol. 2 No. 5.

Shahbaz, M. and Lean, H.H. (2012), "Does financial development increase energy consumption? The role of industrialization and urbanization in Tunisia", Energy Policy, Vol. 40, pp. 473-479.

The World Bank (2015), "World development indicators", available at: http://data.worldbank.org

Wang, Q. (2014), "Effects of urbanisation on energy consumption in China”, Energy Policy, Vol. 65, pp. 332-339, doi: 10.1016/j.enpol.2013.10.005.

Wang, H., Ang, B.W. and Su, B. (2017), "Assessing drivers of economy-wide energy use and emissions: IDA versus SDA”, Energy Policy, Vol. 107, pp. 585-599.

Wang, P., Wu, W., Zhu, B. and Wei, Y. (2013), "Examining the impact factors of energy-related $\mathrm{CO}_{2}$ emissions using the STIRPAT model in Guangdong Province, China", Applied Energy, Vol. 106, pp. 65-71, doi: 10.1016/j.apenergy.2013.01.036. 
Yang, J., Zhang, W. and Zhang, Z. (2016), "Impacts of urbanization on renewable energy consumption in China", Journal of Cleaner Production, Vol. 114, pp. 443-451.

York, R. (2007), "Demographic trends and energy consumption in European Union Nations, 1960-2025", Social Science Research, Vol. 36 No. 3, pp. 855-872.

York, R., Rosa, E.A. and Dietz, T. (2003), "STIRPAT, IPAT and ImPACT: analytic tools for unpacking the driving forces of environmental impacts", Ecological Economics, Vol. 46 No. 3, pp. 351-365.

Zeng, S., Liu, Y., Liu, C. and Nan, X. (2017), "A review of renewable energy investment in the BRICS countries: history, models, problems and solutions", Renewable and Sustainable Energy Reviews, Vol. 74, pp. 860-887.

\section{Further reading}

Adom, P.K., Bekoe, W. and Akoena, S.K.K. (2012), "Modelling aggregate domestic electricity demand in Ghana: an autoregressive distributed lag bounds cointegration approach”, Energy Policy, Vol. 42, pp. 530-537.

Al-Mulali, U., Fereidouni, H.G., Lee, J.Y.M. and Sab, C.N.B.C. (2013), "Exploring the relationship between urbanization, energy consumption, and $\mathrm{CO}_{2}$ emission in MENA countries", Renewable and Sustainable Energy Reviews, Vol. 23, pp. 107-112.

Asif, M., Sharma, R.B. and Adow, A.H.E. (2015), "An empirical investigation of the relationship between economic growth, urbanization, energy consumption, and $\mathrm{CO}_{2}$ emission in GCC countries: a panel data analysis", Asian Social Science, Vol. 11 No. 21.

Belloumi, M. and Alshehry, A. (2016), "The impact of urbanization on energy intensity in Saudi Arabia”, Sustainability, Vol. 8 No. 4, p. 375.

Burney, N.A. (1995), "Socioeconomic development and electricity consumption a cross-country analysis using the random coefficient method", Energy Economics, Vol. 17 No. 3, pp. 185-195.

Creutzig, F., Baiocchi, G., Bierkandt, R., Pichler, P.-P. and Seto, K.C. (2015), "Global typology of urban energy use and potentials for an urbanization mitigation wedge", Proceedings of the National Academy of Sciences, Vol. 112 No. 20, pp. 6283-6288.

Fang, W.S., Miller, S.M. and Yeh, C.-C. (2012), "The effect of ESCOs on energy use", Energy Policy, Vol. 51, pp. 558-568.

Ghosh, S. and Kanjilal, K. (2014), "Long-term equilibrium relationship between urbanization, energy consumption and economic activity. Empirical evidence from India”, Energy, Vol. 66, pp. 324-331.

Imai, H. (1997), "The effect of urbanization on energy consumption", Journal of Population Problems, Vol. 53 No. 2, pp. $43-49$.

Jia Yi Ng (2017), "Influence of El Nino on global hydropower production, environmental research letter", Volume 12, Number 3; Asia - Pacific region: overview of El Nino Responses, July 2016, IASC regional Network for Asia - Pacific.

Jiang, L. and O'Neill, B.C. (2007), "Impacts of demographic trends on US household size and structure", Population and Development Review, Vol. 33 No. 3, pp. 567-591.

Jiang, Z. and Lin, B. (2012), "China's energy demand and its characteristics in the industrialization and urbanization process”, Energy Policy, Vol. 49, pp. 608-615.

Kenworthy, J.R. and Laube, F.B. (1996), "Automobile dependence in cities: an international comparison of urban transport and land use patterns with implications for sustainability", Environmental Impact Assessment Review, Vol. 16 Nos 4/6, pp. 279-308.

Li, H., Mu, H. and Zhang, M. (2011), “Analysis of China's energy consumption impact factors”, Procedia Environmental Sciences, Vol. 11, pp. 824-830.

$\mathrm{Li}, \mathrm{K}$. and Lin, B. (2015), "Impacts of urbanization and industrialization on energy consumption/ $\mathrm{CO}_{2}$ emissions: does the level of development matter?", Renewable and Sustainable Energy Reviews, Vol. 52, pp. 1107-1122. 
Lin, C., Chen, W.C., Liu, S.C., Liou, Y.A., Liu, G.R. and Lin, T.H. (2008), "Numerical study of the impact of urbanization on the precipitation over Taiwan", Atmospheric Environment, Vol. 42 No. 13, pp. 2934-2947.

Liu, F.L. and Ang, B.W. (2003), "Eight methods for decomposing the aggregate energy-intensity of industry", Applied Energy, Vol. 76 Nos 1/3, pp. 15-23.

Muhammad, S. (2015), "The effect of urbanization, affluence and trade openness on energy consumption - Malaysia - 2015", available at: https://mpra.ub.uni-muenchen.de/62743/

Muhammad, S., S., A. and Solarin, (2013), "Trivariate causality between economic growth, urbanisation and electricity consumption in Angola: cointegration and causality analysis", MPRA Paper No. 45580, posted 27, March 2013 05:08 UTC.

Newman, P. and Kenworthy, J.R. (1998), Sustainability and Cities. Overcoming Automobile Dependence/ Peter Newman and Jeffrey Kenworthy, Island Press, Washington, DC.

O’Neill, B.C., Ren, X., Jiang, L. and Dalton, M. (2012), “The effect of urbanization on energy use in India and China in the iPETS model", Energy Economics, Vol. 34, pp. S339-S345.

Sadorsky, P. (2013), "Do urbanization and industrialization affect energy intensity in developing countries?”, Energy Economics, Vol. 37, pp. 52-59.

Sharif Hossain, M. (2011), "Panel estimation for $\mathrm{CO}_{2}$ emissions, energy consumption, economic growth, trade openness and urbanization of newly industrialized countries", Energy Policy, Vol. 39 No. 11, pp. 6991-6999.

Shen, L., Cheng, S., Gunson, A.J. and Wan, H. (2005), "Urbanization, sustainability and the utilization of energy and mineral resources in China", Cities, Vol. 22 No. 4, pp. 287-302.

Tay, S.S.C. and Tijaja, J.P. (2017), "Global megatrends - implications for the ASEAN economic community", ISBN 978-602-6392-67-1.

Su, B., Meng, F., Thomson, E., Zhou, D. and Zhou, P. (2016), "Measuring china's regional energy and carbon emission efficiency with DEA models: a survey", Applied Energy, Vol. 183, pp. 1-21.

Sun, C., Ouyang, X., Cai, H., Luo, Z. and Li, A. (2014), "Household pathway selection of energy consumption during urbanization process in China", Energy Conversion and Management, Vol. 84, pp. 295-304.

Wang, Q., Zeng, Y.E. and Wu, B.W. (2016), "Exploring the relationship between urbanization, energy consumption, and $\mathrm{CO}_{2}$ emissions in different provinces of China", Renewable and Sustainable Energy Reviews, Vol. 54, pp. 1563-1579.

\section{Corresponding author}

Phuong Minh Khuong can be contacted at: khuong.phuong@partner.kit.edu

For instructions on how to order reprints of this article, please visit our website: 